\title{
Redefining lumbar spinal stenosis as a developmental syndrome: an MRI-based multivariate analysis of findings in 709 patients throughout the 16- to 82-year age spectrum
}

\author{
Sameer Kitab, MD, ${ }^{1}$ Bryan S. Lee, MD,,$^{2,3}$ and Edward C. Benzel, MD ${ }^{2,3}$ \\ ${ }^{1}$ Scientific Council of Orthopedics, Baghdad, Iraq; ${ }^{2}$ Department of Neurosurgery, Cleveland Clinic Lerner College of Medicine \\ of Case Western Reserve University, Cleveland Clinic; and ${ }^{3}$ Center for Spine Health, Neurological Institute, Cleveland Clinic, \\ Cleveland, Ohio
}

OBJECTIVE Using an imaging-based prospective comparative study of 709 eligible patients that was designed to assess lumbar spinal stenosis (LSS) in the ages between 16 and 82 years, the authors aimed to determine whether they could formulate radiological structural differences between the developmental and degenerative types of LSS.

METHODS MRI structural changes were prospectively reviewed from 2 age cohorts of patients: those who presented clinically before the age of 60 years and those who presented at 60 years or older. Categorical degeneration variables at L1-S1 segments were compared. A multivariate comparative analysis of global radiographic degenerative variables and spinal dimensions was conducted in both cohorts. The age at presentation was correlated as a covariable.

RESULTS A multivariate analysis demonstrated no significant between-groups differences in spinal canal dimensions and stenosis grades in any segments after age was adjusted for. There were no significant variances between the 2 cohorts in global degenerative variables, except at the L4-5 and L5-S1 segments, but with only small effect sizes. Agerelated degeneration was found in the upper lumbar segments (L1-4) more than the lower lumbar segments (L4-S1). These findings challenge the notion that stenosis at L4-5 and L5-S1 is mainly associated with degenerative LSS.

CONCLUSIONS Integration of all the morphometric and qualitative characteristics of the 2 LSS cohorts provides evidence for a developmental background for LSS. Based on these findings the authors propose the concept of LSS as a developmental syndrome with superimposed degenerative changes. Further studies can be conducted to clarify the clinical definition of LSS and appropriate management approaches.

https://thejns.org/doi/abs/10.3171/2018.5.SPINE18100

KEYWORDS degenerative lumbar stenosis; developmental lumbar spinal stenosis; developmental syndrome

$\mathrm{L}$ UMBAR spinal stenosis (LSS) is one of the most commonly diagnosed spinal disorders in the adult population ${ }^{14,20,35}$ and can be categorized based on either the location of the pathology or the etiology of the stenosis. $^{13,24,43}$ The most common type of LSS is degenerative and entails narrowing of the central canal, lateral recess, and/or neural foramen due to disc herniation, facet hypertrophy, ligamentum hypertrophy, and/or spondylolisthesis. ${ }^{13,24,43}$ Furthermore, the eligibility criteria for LSS are related to age demographics, and degenerative stenosis commonly presents after the age of 60 years. ${ }^{14,24,45}$

On the other hand, developmental LSS entails nar- rowing of the canal secondary to bone dysplasia., ${ }^{2,4,7,25,38,39}$ Arnoldi et al. initially defined developmental LSS as developmental narrowing of the spinal canal, with the early presentation of neurogenic symptoms and minimal radiological findings of degenerative spondylotic changes. ${ }^{2}$

Nearly all elderly patients exhibit radiological manifestations of spine degeneration. However, a relatively small percentage develop the clinical syndrome of spinal stenosis. ${ }^{14,20,24,35,45}$ Genetic polymorphisms may explain why some individuals are at a higher risk of developing symptomatic degenerative LSS, but this concept is only speculative and yet to be unraveled. . $^{418,22,24,26,30,31,34,41,42,45}$

ABBREVIATIONS BCSA = vertebral body cross-sectional area; CCSA = spinal canal cross-sectional area; $\mathrm{LSS}=$ lumbar spinal stenosis; TDSS = total degenerative scale score.

SUBMITTED February 1, 2018. ACCEPTED May 22, 2018.

INCLUDE WHEN CITING Published online September 14, 2018; DOI: 10.3171/2018.5.SPINE18100. 
Although clinical examinations are often utilized to aid the diagnosis of LSS, imaging modalities, such as MRI, are necessary for a definitive diagnosis. $2,4,6,7,13,14,24,25,35,45$ Imaging modalities should be used judiciously, however, as radiographic findings of LSS do not always correlate with clinical findings, and they can be more extensive than the actual clinical scenario, ${ }^{6,13,14,20,24,35,45}$ as they may represent developmental rather than degenerative manifestatons. $6,12,14,20,24,35,45$ In the degenerative LSS type, MRI findings represent the results of a spondylotic process culminating in the stenotic effect. ${ }^{14,20,24,35,45}$ Developmental LSS, on the other hand, starts with a smaller buffer. 2,4,7,25, ${ }^{38-40}$ However, the morphological characteristics of lumbar segment components in the developmental LSS type are not well characterized. ${ }^{4,7,25,38-40}$

We propose that reviewing the morphological manifestations throughout the age spectrum based on the MRI findings would provide further evidence of the natural history of the LSS development and help clearly define LSS types.

\section{Methods}

A prospective lumbar MRI study was conducted in clinically symptomatic LSS patients over the 16- to 82year age spectrum. Patients were consecutively enrolled at a single institution and divided into 2 cohorts based on age demographics: patients presenting before the age of 60 years, and at the age of or after 60 years. A total of 709 patients met the inclusion criteria of clinically diagnosed neurogenic claudication, with varying degrees of pain, weakness, fatigability, and sensory changes for the duration of at least 2 months, followed by radiographic confirmation and diagnosis with MRI. Patients with axial back pain only, sacroiliac disorders, vascular claudication, trauma, tumor, or previous spinal surgery were excluded. The study was conducted under Cleveland Clinic institutional review board approval, and in accordance with that approval, all patients were evaluated after informed consent was obtained.

The 2 LSS cohorts were compared qualitatively and semi-quantitatively with an MRI radiographic analysis of lumbar segment components from L1 to S1. Sagittal T1weighted spin-echo, sagittal T2-weighted fast spin-echo, and axial T2-weighted fast spin-echo (1.5-T) sequences were used for assessment in each case. All variables were analyzed by 2 spine fellowship-trained surgeons, who were blinded to classification types. The Schizas qualitative grading system was used to evaluate the extent of neural compression and severity of stenosis. ${ }^{36}$ To be consistent with other degenerative grades in MRI radiological analysis, alphabet letters in the grades were converted to numbers (grades A-D were converted to numerical values of 1-4) (Table 1). Moreover, to minimize selection and inclusion bias, subtypes within the mild stenosis grade were excluded. Other variables tested included disc degeneration grades,${ }^{43}$ presence of disc herniation, ${ }^{9}$ disc height, endplate shape, irregularities and sclerosis, Schmorl's nodes, 15,44 Modic changes, ${ }^{11,32}$ and facet degeneration grades. ${ }^{5,29,43} \mathrm{~A}$ chi-square test for independence was performed to compare the observed frequencies of degenerative categorical
TABLE 1. Results summary of the frequency of different Schizas grades of stenosis in the 2 age cohorts at L1-S1

\begin{tabular}{|c|c|c|c|c|c|}
\hline $\begin{array}{l}\text { Segment \& } \\
\text { Age Cohort }\end{array}$ & $\begin{array}{c}\text { Grade } \\
1\end{array}$ & $\begin{array}{c}\text { Grade } \\
2\end{array}$ & $\begin{array}{c}\text { Grade } \\
3\end{array}$ & $\begin{array}{c}\text { Grade } \\
4\end{array}$ & $\begin{array}{l}\text { Grades } \\
3 \& 4^{*}\end{array}$ \\
\hline \multicolumn{6}{|l|}{ L1-2 } \\
\hline$<60$ yrs & $93.6 \%$ & $2.3 \%$ & $3.1 \%$ & $0.2 \%$ & $3.3 \%$ \\
\hline$\geq 60 \mathrm{yrs}$ & $88.2 \%$ & $5.0 \%$ & $4.5 \%$ & $0.9 \%$ & $5.4 \%$ \\
\hline Total & $91.9 \%$ & $3.1 \%$ & $3.5 \%$ & $0.4 \%$ & $3.9 \%$ \\
\hline \multicolumn{6}{|l|}{ L2-3 } \\
\hline$<60$ yrs & $79.5 \%$ & $7.0 \%$ & $10.3 \%$ & $2.5 \%$ & $12.8 \%$ \\
\hline$\geq 60 \mathrm{yrs}$ & $60.5 \%$ & $10.9 \%$ & $23.6 \%$ & $4.1 \%$ & $27.7 \%$ \\
\hline Total & $73.6 \%$ & $8.2 \%$ & $14.4 \%$ & $3.0 \%$ & $17.4 \%$ \\
\hline \multicolumn{6}{|l|}{ L3-4 } \\
\hline$<60$ yrs & $37.2 \%$ & $9.2 \%$ & $39.8 \%$ & $13.3 \%$ & $53.1 \%$ \\
\hline$\geq 60 \mathrm{yrs}$ & $20.9 \%$ & $5.5 \%$ & $53.2 \%$ & $19.5 \%$ & $72.7 \%$ \\
\hline Total & $32.1 \%$ & $8.1 \%$ & $44.0 \%$ & $15.3 \%$ & $59.3 \%$ \\
\hline \multicolumn{6}{|l|}{ L4-5 } \\
\hline$<60$ yrs & $4.7 \%$ & $3.1 \%$ & $49.9 \%$ & $42.1 \%$ & $92 \%$ \\
\hline$\geq 60 \mathrm{yrs}$ & $3.6 \%$ & $3.6 \%$ & $38.2 \%$ & $54.5 \%$ & $92.7 \%$ \\
\hline Total & $4.4 \%$ & $3.3 \%$ & $46.3 \%$ & $46.0 \%$ & $92.3 \%$ \\
\hline \multicolumn{6}{|l|}{ L5-S1 } \\
\hline$<60$ yrs & $62.6 \%$ & $10.9 \%$ & $17.2 \%$ & $8.8 \%$ & $26.0 \%$ \\
\hline$\geq 60$ yrs & $56.4 \%$ & $15.9 \%$ & $20.5 \%$ & $6.4 \%$ & $26.9 \%$ \\
\hline Total & $60.7 \%$ & $12.4 \%$ & $18.2 \%$ & $8.1 \%$ & $26.3 \%$ \\
\hline
\end{tabular}

Schizas grades A-D were converted to numerical values of 1-4.

* Combined percentage of grades 3 and 4 (severe stenosis).

variables between the 2 age cohorts, with specific emphasis on the effect size.

In exploring the between-groups differences of spinal canal dimensions, Pillai's trace statistic was used to determine the significance in multivariate testing; this statistic is more robust in analyzing data from samples of unequal size. Spinal canal dimensions were expressed as ratios with vertebral body dimensions to neutralize for a possible measurement bias due to ethnic, race, or body mass effects (Figs. 1 and 2). ${ }^{25} \mathrm{~A}$ one-way between-groups multivariate analysis of variance was also conducted to include a total degenerative scale score (TDSS). ${ }^{19}$ This score, a continuous variable, is the summation of tested variable scores listed in (Table 2) with a potential range of $0-25$, and with the Cronbach alpha coefficient for intra- and interobserver reliability testing reported as 0.829 , suggesting reliable internal consistency in measurements.

Age was further controlled for as a covariate in the multivariate analysis mode. A p value $\leq 0.05$ was accepted as indicating statistical significance. The statistical analyses were performed with IBM SPSS for Windows (version 22.0, IBM Corp.) statistical software.

\section{Results}

In our 709 patients that met the inclusion criteria, the mean age at presentation was $50.8 \pm 12.85$ years, with a normal distribution curve; $43.1 \%$ of the total cohort of patients were male, and $56.9 \%$ were females. Of the 709 


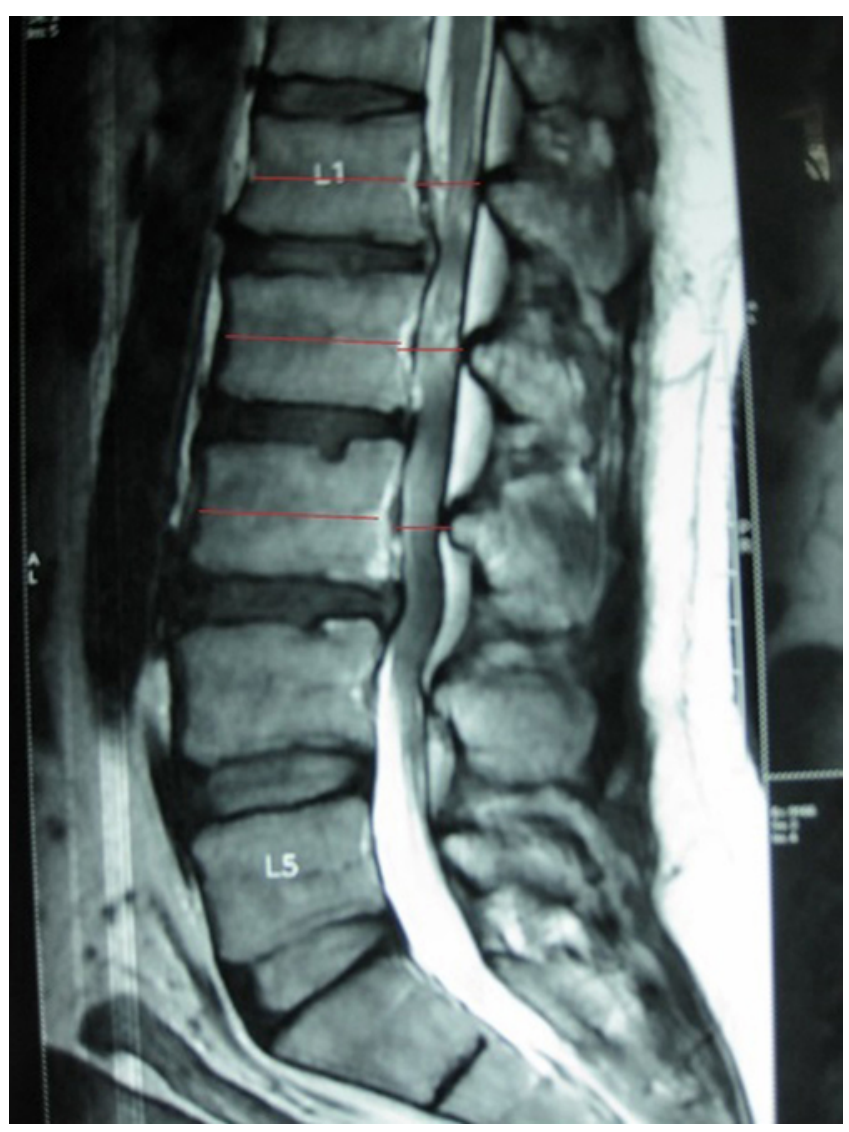

FIG. 1. Sagittal T2-weighted MR image showing the measurement of anteroposterior spinal canal diameter (APC) and anteroposterior vertebral body diameter (APB).

patients, $480(67.7 \%)$ were younger than 60 years $(43.8 \%$ of these patients were male and $56.2 \%$ were female), and $229(32.3 \%)$ were 60 years or older $(41.6 \%$ male, $58.4 \%$ female).

Stenosis frequency and qualitative stenosis grades for both cohorts revealed that the L4-5 segment had the highest frequency of stenosis, followed by L3-4, then L5-S1 (Table 1). There was no significant association between the frequencies of stenosis grades and the 2 age cohorts at L5-S1, while there was a significant difference at L4-5 but with a small effect size (Table 2). These findings challenge the notion that stenotic changes at L4-5 and L5-S1 are mainly associated with a spondylotic, degenerative process. . $^{6,14,20,24,35}$

The frequency of severe stenosis (combined percentages of Schizas ${ }^{36}$ grades 3 and 4) at upper lumbar segments (L1-3) was higher for the older age cohort, whereas the frequency of severe stenosis at lower lumbar segments (L4-S1) was similar for both stenosis cohorts (Table 1). This difference implicates an age-related association with stenosis grades more influencing upper lumbar segments.

Decreasing spinal canal dimensions and the increasing frequencies of stenosis involvements down to L4-5 segments in all patients is contrary to the normal pattern of increasing spinal canal dimensions from L1 to L5 and implies a global maldevelopment of the spinal canal. This morphology was present in both cohorts (Tables 1 and 3).

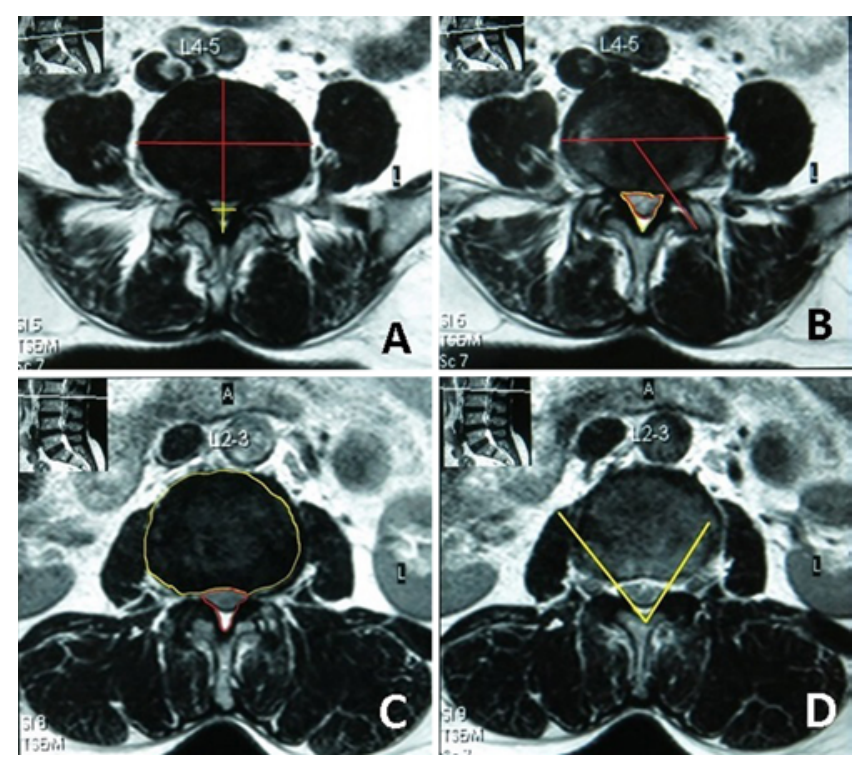

FIG. 2. Axial MRI (T2-weighted) detailing lumbar spinal canal variables tested. A: Anteroposterior spinal canal length (APCa)/anteroposterior vertebral body length (APBa). B: Transverse spinal canal width (TCW)/ transverse vertebral body width (TBW). C: Spinal canal cross-sectional area (CCSA)/vertebral body cross-sectional area (BCSA) with thecal sac cross-sectional area (TCSA)/CCSA. D: Interlaminar angle.

Multivariate analyses of quantitative variables concerned with relative spinal canal dimensions and areas on both sagittal and axial MR images revealed no significant differences between the 2 cohorts, except for the ratio of spinal canal cross-sectional area (CCSA) to vertebral body cross-sectional area (BCSA) at L2-3 with a small effect size $(p=0.002$, partial eta-squared $=0.031)$. The age cohorts could only explain $3.1 \%$ of the variance in CCSA/ BCSA at L2-3 (Table 3). There was a significant difference regarding the TDSS at L4-5 with a small effect size and at L5-S1 with a medium effect size. Inspection of the mean scores demonstrated that, compared to the younger cohort, the older age cohort had only a mild increase in the mean score (difference of 1.56) for L4-5 and a greater increase (difference of 1.8) for L5-S1.

Qualitative evaluation of spinal canal dimensions concerning posterior elements, facet inclination, and interlaminar angles assembled from axial MR images revealed identical spinal canal morphologies in the 2 cohorts. ${ }^{19}$ These commonalities of spinal canal morphologies imply a common developmental background.

The relevant data in this study suggest that the agerelated lumbar intervertebral disc degeneration influences variable scores at the upper lumbar segments (L1-4) more than at the lower lumbar segments (L4-S1) (Table 2). This is contrary to what is commonly believed, as reported in the literature. . $^{2,4,67,13,24,25,27,45}$ At the lower lumbar segments, there were no significant differences between the 2 cohorts in the findings that were previously thought to be characteristic of age-associated degeneration, such as disc herniation, loss of disc height, endplate changes, and Schmorl's nodes (Table 2).,$_{8,9,11,15,29,32,43,44}$ The frequency of radiological degeneration in the facet joints was high in both cohorts $(65 \%-80 \%)$. There was a significant 
TABLE 2. Pearson's chi-square test for independence (or with Yates' correction for continuity) with special emphasis on the effect size (strength of association) between the tested variable and age cohorts at L1-S1

\begin{tabular}{|c|c|c|c|}
\hline Variable \& Level & $\chi^{2}$ & $\begin{array}{c}\mathrm{p} \\
\text { Value }\end{array}$ & $\begin{array}{l}\text { Cramer's V Value } \\
\text { or Phi Coefficient } \\
\text { (effect size) }\end{array}$ \\
\hline \multicolumn{4}{|c|}{$\begin{array}{l}\text { Pfirrmann's degenerative disc } \\
\text { grades }\end{array}$} \\
\hline $\mathrm{L} 1-2$ & 132.9 & $<0.005$ & 0.34 (medium) \\
\hline L2-3 & 106.6 & $<0.005$ & 0.38 (medium) \\
\hline L3-4 & 83.4 & $<0.005$ & 0.34 (medium) \\
\hline L4-5 & 33.4 & $<0.005$ & 0.21 (small) \\
\hline L5-S1 & 33.4 & $<0.005$ & 0.21 (small) \\
\hline \multicolumn{4}{|c|}{$\begin{array}{l}\text { Pathria's facet degenerative } \\
\text { grades }{ }^{29,43}\end{array}$} \\
\hline $\mathrm{L} 1-2$ & 18.98 & $<0.005$ & 0.16 (small) \\
\hline L2-3 & 29.32 & $<0.005$ & 0.20 (small) \\
\hline L3-4 & 21.37 & $<0.005$ & 0.17 (small) \\
\hline L4-5 & 16.16 & 0.001 & 0.15 (small) \\
\hline L5-S1 & 8.08 & 0.044 & 0.11 (small) \\
\hline \multicolumn{4}{|c|}{$\begin{array}{l}\text { Schizas' qualitative stenosis } \\
\text { grades }{ }^{36}\end{array}$} \\
\hline L1-2 & 7.29 & 0.121 & 0.10 \\
\hline L2-3 & 30.44 & $<0.005$ & 0.21 (small) \\
\hline L3-4 & 25.78 & $<0.005$ & 0.19 (small) \\
\hline L4-5 & 10.612 & 0.031 & 0.12 (small) \\
\hline L5-S1 & 6.718 & 0.15 & 0.09 \\
\hline \multicolumn{4}{|c|}{ Endplate shape \& irregularity } \\
\hline L1-2 & 23.47 & $<0.005$ & 0.18 (small) \\
\hline L2-3 & 25.00 & $<0.005$ & 0.18 (small) \\
\hline L3-4 & 17.76 & $<0.005$ & 0.16 (small) \\
\hline L4-5 & 2.84 & 0.417 & 0.06 \\
\hline L5-S1 & 5.412 & 0.144 & 0.08 \\
\hline \multicolumn{4}{|c|}{$\begin{array}{l}\text { Disc height divided into quar- } \\
\text { ters compared to reference } \\
\text { normal disc height level }\end{array}$} \\
\hline $\mathrm{L} 1-2$ & 9.63 & 0.022 & 0.10 (small) \\
\hline L2-3 & 13.13 & 0.004 & 0.10 (small) \\
\hline L3-4 & 3.57 & 0.312 & 0.07 \\
\hline L4-5 & 11.65 & 0.009 & 0.13 (small) \\
\hline L5-S1 & 14.17 & 0.003 & 0.14 (small) \\
\hline \multicolumn{4}{|c|}{ Modic endplate changes ${ }^{11,32}$} \\
\hline L1-2 & 9.31 & 0.025 & 0.11 (small) \\
\hline L2-3 & 9.39 & 0.052 & 0.11 (small) \\
\hline L3-4 & 13.69 & 0.008 & 0.13 (small) \\
\hline L4-5 & 3.02 & 0.555 & 0.06 \\
\hline L5-S1 & 13.29 & 0.010 & 0.13 (small) \\
\hline
\end{tabular}

\section{» CONTINUED FROM PREVIOUS COLUMN}

TABLE 2. Pearson's chi-square test for independence (or with Yates' correction for continuity) with special emphasis on the effect size (strength of association) between the tested variable and age cohorts at L1-S1

\begin{tabular}{cccc}
\hline \multicolumn{1}{c}{$\begin{array}{c}\text { Variable \& Level } \\
\text { Value }\end{array}$} & $\begin{array}{c}\text { Cramer's V Value } \\
\text { or Phi Coefficient } \\
\text { (effect size) }\end{array}$ \\
\hline $\begin{array}{c}\text { Schmorl's nodes }{ }^{15,44} \text { frequen- } \\
\text { cy difference, w/ Yates' } \\
\text { continuity correction }\end{array}$ & & & \\
\hline L1-2 & 0.08 & 0.778 & -0.01 \\
\hline L2-3 & 5.43 & 0.020 & -0.09 (small) \\
\hline L3-4 & 3.43 & 0.064 & -0.04 \\
\hline L4-5 & 0.99 & 0.319 & -0.04 \\
\hline L5-S1 & 0.10 & 0.75 & -0.023 \\
\hline $\begin{array}{c}\text { Disc hernias }{ }^{9} \text { frequency differ- } \\
\text { ence, w/ Yates' continuity }\end{array}$ & & & \\
correction & & & \\
\hline L1-2 & 0.22 & 0.641 & 0.023 \\
\hline L2-3 & 5.03 & 0.025 & 0.09 (small) \\
\hline L3-4 & 0.00 & 1.00 & 0.001 \\
\hline L4-5 & 1.19 & 0.315 & -0.041 \\
\hline L5-S1 & 3.366 & 0.067 & -0.072 \\
\hline
\end{tabular}

Effect size statistics utilizing Cramer's $V$ or phi correlation coefficient (for 2 by 2 tables).

difference in facet degeneration grades across all lumbar segments with a statistically small effect size (Table 2). The weak association between the stenosis types and facet degeneration grades in all lumbar segments makes radiological differences essentially irrelevant to either stenosis type.

The L5-S1 segment in this study was shown to have peculiar characteristics. Stenosis frequency was lower at L5-S1 than at the adjacent L3-5 segments (Tables 1 and 2). Our study results showed lower frequencies of all degeneration variables compared with adjacent L3-5 segments regardless of the age cohorts. This should be accounted for by the coronal orientation of the L5-S1 facet joints. However, the lower incidence of stenosis at L5-S1 challenges the notion that local biomechanical environment influences degeneration. ${ }^{33}$

Furthermore, a one-way between-groups multivariate analysis of covariance was performed to investigate differences between the 2 cohorts while statistically controlling for age. Age was assumed to influence spinal canal dimensions for the older age cohort. Preliminary checks were conducted to ensure that there was no violation of the assumptions. After adjusting for age there was no significant difference between the 2 cohorts with respect to vertebral dimensions and qualitative stenosis grading.

\section{Discussion}

The radiological findings and data analysis from our study suggest that radiological manifestations of a narrow 
TABLE 3. Results of one-way between-groups multivariate analysis of variance with adjusted alpha level

\begin{tabular}{cccl}
\hline Level & Pillai's Test Value & $p$ Value & \multicolumn{1}{c}{ Tests of Between-Groups Effects } \\
\hline L1-2 & 0.071 & 0.132 & No significant difference \\
\hline L2-3 & 0.054 & 0.037 & CCSA/BCSA: $F=9.682, p=0.002, \eta p^{2}=0.020$ (small effect size) \\
\hline L3-4 & 0.026 & No significant difference \\
\hline L4-5 & 0.065 & $<0.005$ & TDSS: $F=26.93, p<0.05, \eta p^{2}=0.056$ \\
\hline L5-S1 & 0.114 & $<0.005$ & TDSS: $F=28.67, p<0.05, \eta p^{2}=0.079$ \\
\hline
\end{tabular}

$n p^{2}=$ partial eta-squared

A p value $<0.05$ indicates a significant difference between the 2 age cohorts on the combination of dependent variables. The variables listed are the only ones that showed a significant difference on multivariate analysis.

spinal canal in the younger age cohort cannot be attributed to degeneration only. Furthermore, the age at presentation and the natural history of the LSS syndrome are largely unpredictable and are further compounded by the neural tissue tolerance to the combined effects of central stenosis. ${ }^{20,35}$

In our study, there was no significant difference of quantitative spinal canal characteristics tested between the 2 cohorts. Age-related degenerative radiological changes influenced upper lumbar segments L1-4 rather than lower segments L4-S1. There was no or only minimal significant difference in degenerative radiological variables and stenosis grades between the 2 cohorts at segments commonly involved with stenosis (L3-5).

These findings cast doubt on degeneration as the only etiopathology, and any attempt to formulate a clear differentiation between the 2 cohorts is challenging. Spinal canal development, however, starts early in life, , $16,17,21,23$ and recent studies implicated a genetic background for lumbar central stenosis. 1,4,12, $18,21,23,27,28,30,31,34,37,41,42$ Battié et al. demonstrated that central LSS is highly genetic and that disc degeneration and height appear to represent one pathway through which genes influence spinal canal dimensions. ${ }^{4}$ A plausible theory is to rely on the developmental concept. ${ }^{4,7,25,31,34,38-42}$ We propose through our findings that a developmentally narrow spinal canal is the basic characteristic that predisposes patients to develop the clinical syndrome in LSS.

A developmental and degenerative etiology, however, can exist in the same patient. , $^{2,7,25,27,38-40}$ In other words, a developmental foundation is compounded by further degeneration. This is likely very common, thus confusing the overall etiological picture and blurring the boundaries between the 2 entities. ${ }^{2,4,25,27}$ This is reflective of the conflict in the literature regarding the poorly defined developmental stenosis..$^{2,4,25,27}$ The high rate of disc hernias or hypertrophic facets at segments commonly involved with stenosis (L3-4 and L4-5) may induce the clinical syndrome in an asymptomatic patient at a younger age. This may gain importance in the modern era of interest in minimum access spine surgery (MIS). It is likely uncertain whether these patients should undergo discectomy only via an MIS approach or would need more aggressive decompression. 9,27

The basic pathoanatomy in developmental stenosis is related to the confined spaces available for neural elements. ${ }^{2,4,6,7,13,14,24,25,35,45}$ Recently, Luk and Samartzis ${ }^{30}$ in- troduced the concept of lumbar intervertebral disc "dysgeneration," defined as early identification of a black or unhydrated or dehydrated disc, with characteristics that vary from those of lumbar intervertebral disc degeneration. In our study basic radiological manifestations of lumbar components in the younger age cohort may represent potential failure of full development early in life. Such radiological manifestations are likely to persist throughout the life span. Radiological degenerative manifestations in younger patients should be interpreted with caution to avoid the overuse of fusion. Similarly, the lower frequency of stenosis and degeneration at L5-S1 has a particular significance concerning the need for incorporation of the lumbosacral segment in spine fusions.

The importance of defining LSS as a developmental syndrome cannot be overemphasized. Defining LSS subtypes according to surface radiological measurements only is a shortcoming. Radiological degenerative and dysgenerative manifestations in the developmental LSS subtype are poorly characterized in the literature. ${ }^{1-14}$ To the best of our knowledge, this is the first large-scale study to compare spinal canal morphometric parameters as well as lumbar degenerative manifestations between younger and older cohorts. Comparative analysis of the 2 age cohorts demonstrated no or minimal significant difference in the radiological degeneration of the lumbar segment components. Our study showed that the biological age of a stenotic lumbar segment does not correlate with the actual chronologic age of the patient. Redefining lumbar stenosis as a developmental syndrome regardless of radiological findings mandates further studies to define "true superimposed degeneration." Such re-definition is likely to influence clinical decision-making and fusion indications. From an analytical perspective, the use of a defined clinical syndrome is essential for recruiting specific and homogeneous patient populations in validated clinical trials..$^{14}$

Our study was not without limitations. Lower segments may have undergone significant degenerative changes earlier, such that differences cannot be detected with a cutoff at 60 years of age. Age group stratification or further longitudinal study is warranted to assess the natural history of development. Schizas qualitative grading was utilized in the study for radiologic confirmation of included LSS cases. It takes into account the more relevant root-to-CSF ratio indicating neural compression. Direct surface measurements for LSS confirmation are controversial in the literature and, alone, fail to take into account the more 
relevant root-CSF ratio. ${ }^{36}$ Moreover, the study design prevents inferring sound attributes of pain correlation with lumbar MRI changes analyzed. Although our results support a developmental origin for the subset of MRI changes, a developmental causality can only be suggested.

\section{Conclusions}

Integration of all the morphometric and qualitative characteristics of the 2 LSS cohorts provides evidence for a developmental background for LSS. With such findings we propose the concept of LSS as a developmental syndrome with superimposed degenerative changes. Further longitudinal studies to assess the natural history of development and to clarify the clinical definition of LSS and management approaches should be appropriate.

\section{References}

1. Abbas J, Hamoud K, May H, Hay O, Medlej B, Masharawi Y, et al: Degenerative lumbar spinal stenosis and lumbar spine configuration. Eur Spine J 19:1865-1873, 2010

2. Arnoldi CC, Brodsky AE, Cauchoix J, Crock HV, Dommisse GF, Edgar MA, et al: Lumbar spinal stenosis and nerve root entrapment syndromes. Definition and classification. Clin Orthop Relat Res (115):4-5, 1976

3. Atilla B, Yazici M, Kopuz C, Bariş S, Balçik C: The shape of the lumbar vertebral canal in newborns. Spine (Phila Pa 1976) 22:2469-2472, 1997

4. Battié MC, Ortega-Alonso A, Niemelainen R, Gill K, Levalahti E, Videman T, et al: Lumbar spinal stenosis is a highly genetic condition partly mediated by disc degeneration. Arthritis Rheumatol 66:3505-3510, 2014

5. Boden SD, Riew KD, Yamaguchi K, Branch TP, Schellinger D, Wiesel SW: Orientation of the lumbar facet joints: association with degenerative disc disease. J Bone Joint Surg Am 78:403-411, 1996

6. Butler D, Trafimow JH, Andersson GB, McNeill TW, Huckman MS: Discs degenerate before facets. Spine (Phila Pa 1976) 15:111-113, 1990

7. Cheung JP, Samartzis D, Shigematsu H, Cheung KM: Defining clinically relevant values for developmental spinal stenosis: a large-scale magnetic resonance imaging study. Spine (Phila Pa 1976) 39:1067-1076, 2014

8. Cheung KM, Karppinen J, Chan D, Ho DW, Song YQ, Sham $\mathrm{P}$, et al: Prevalence and pattern of lumbar magnetic resonance imaging changes in a population study of one thousand fortythree individuals. Spine (Phila Pa 1976) 34:934-940, 2009

9. Dai LY, Ni B, Jia LS, Liu HK: Lumbar disc herniation in patients with developmental spinal stenosis. Eur Spine J 5:308-311, 1996

10. Davies BM, Atkinson RA, Ludwinski F, Freemont AJ, Hoyland JA, Gnanalingham KK: Qualitative grading of disc degeneration by magnetic resonance in the lumbar and cervical spine: lack of correlation with histology in surgical cases. $\mathbf{B r}$ J Neurosurg 30:414-421, 2016

11. Dudli S, Fields AJ, Samartzis D, Karppinen J, Lotz JC: Pathobiology of Modic changes. Eur Spine J 25:3723-3734, 2016

12. Eisenstein S: The morphometry and pathological anatomy of the lumbar spine in South African negroes and caucasoids with specific reference to spinal stenosis. J Bone Joint Surg Br 59:173-180, 1977

13. Fujiwara A, Tamai K, Yamato M, An HS, Yoshida H, Saotome K, et al: The relationship between facet joint osteoarthritis and disc degeneration of the lumbar spine: an MRI study. Eur Spine J 8:396-401, 1999

14. Genevay S, Atlas SJ, Katz JN: Variation in eligibility criteria from studies of radiculopathy due to a herniated disc and of neurogenic claudication due to lumbar spinal stenosis: a structured literature review. Spine (Phila Pa 1976) 35:803811,2010

15. Hamanishi C, Kawabata T, Yosii T, Tanaka S: Schmorl's nodes on magnetic resonance imaging. Their incidence and clinical relevance. Spine (Phila Pa 1976) 19:450-453, 1994

16. Hinck VC, Clark WM Jr, Hopkins CE: Normal interpediculate distances (minimum and maximum) in children and adults. Am J Roentgenol Radium Ther Nucl Med 97:141153,1966

17. Hinck VC, Hopkins CE, Clark WM: Sagittal diameter of the lumbar spinal canal in children and adults. Radiology 85:929-937, 1965

18. Hurxthal LM: Schmorl's nodes in identical twins. Their probable genetic origin. Lahey Clin Found Bull 15:89-92, 1966

19. Jensen RK, Jensen TS, Kjaer P, Kent P: Can pathoanatomical pathways of degeneration in lumbar motion segments be identified by clustering MRI findings. BMC Musculoskelet Disord 14:198, 2013

20. Kalichman L, Cole R, Kim DH, Li L, Suri P, Guermazi A, et al: Spinal stenosis prevalence and association with symptoms: the Framingham Study. Spine J 9:545-550, 2009

21. Karantanas AH, Zibis AH, Papaliaga M, Georgiou E, Rousogiannis S: Dimensions of the lumbar spinal canal: variations and correlations with somatometric parameters using CT. Eur Radiol 8:1581-1585, 1998

22. Karppinen J, Daavittila I, Solovieva S, Kuisma M, Taimela S, Natri A, et al: Genetic factors are associated with modic changes in endplates of lumbar vertebral bodies. Spine (Phila Pa 1976) 33:1236-1241, 2008

23. Kim HK, Park JY, Kuh SU, Chin DK, Kim KS, Cho YE, et al: Changes in spinal canal diameter and vertebral body height with age. Yonsei Med J 54:1498-1504, 2013

24. Kirkaldy-Willis WH, Wedge JH, Yong-Hing K, Reilly J: Pathology and pathogenesis of lumbar spondylosis and stenosis. Spine (Phila Pa 1976) 3:319-328, 1978

25. Kitab SA, Alsulaiman AM, Benzel EC: Anatomic radiological variations in developmental lumbar spinal stenosis: a prospective, control-matched comparative analysis. Spine J 14:808-815, 2014

26. Kraatari M, Skarp S, Niinimäki J, Karppinen J, Männikkö M: A whole exome study identifies novel candidate genes for vertebral bone marrow signal changes (Modic changes). Spine (Phila Pa 1976) 42:1201-1206, 2017

27. Kreiner DS, Shaffer WO, Baisden JL, Gilbert TJ, Summers JT, Toton JF, et al: An evidence-based clinical guideline for the diagnosis and treatment of degenerative lumbar spinal stenosis (update). Spine J 13:734-743, 2013

28. Lee HM, Kim NH, Kim HJ, Chung IH: Morphometric study of the lumbar spinal canal in the Korean population. Spine (Phila Pa 1976) 20:1679-1684, 1995

29. Lee JC, Cha JG, Yoo JH, Kim HK, Kim HJ, Shin BJ: Radiographic grading of facet degeneration, is it reliable?-a comparison of MR or CT grading with histologic grading in lumbar fusion candidates. Spine J 12:507-514, 2012

30. Luk KD, Samartzis D: Intervertebral disc "dysgeneration". Spine J 15:1915-1918, 2015

31. Mayer JE, Iatridis JC, Chan D, Qureshi SA, Gottesman O, Hecht AC: Genetic polymorphisms associated with intervertebral disc degeneration. Spine J 13:299-317, 2013

32. Mok FP, Samartzis D, Karppinen J, Fong DY, Luk KD, Cheung KM: Modic changes of the lumbar spine: prevalence, risk factors, and association with disc degeneration and low back pain in a large-scale population-based cohort. Spine J 16:32-41, 2016

33. Nakipoğlu GF, Karagöz A, Ozgirgin N: The biomechanics of the lumbosacral region in acute and chronic low back pain patients. Pain Physician 11:505-511, 2008 
34. Näkki A, Battié MC, Kaprio J: Genetics of disc-related disorders: current findings and lessons from other complex diseases. Eur Spine J 23 (Suppl 3):S354-S363, 2014

35. North American Spine Society: Evidence Based Clinical Guidelines for Multidisciplinary Spine Care: Diagnosis and Treatment of Degenerative Lumbar Spinal Stenosis. Burr Ridge, IL: North American Spine Society, 2007

36. Schizas C, Theumann N, Burn A, Tansey R, Wardlaw D, Smith FW, et al: Qualitative grading of severity of lumbar spinal stenosis based on the morphology of the dural sac on magnetic resonance images. Spine (Phila Pa 1976) 35:19191924, 2010

37. Siemionow K, An H, Masuda K, Andersson G, Cs-Szabo G: The effects of age, sex, ethnicity, and spinal level on the rate of intervertebral disc degeneration: a review of 1712 intervertebral discs. Spine (Phila Pa 1976) 36:1333-1339, 2011

38. Singh K, Samartzis D, Vaccaro AR, Nassr A, Andersson GB, Yoon ST, et al: Congenital lumbar spinal stenosis: a prospective, control-matched, cohort radiographic analysis. Spine J 5:615-622, 2005

39. Soldatos T, Chalian M, Thawait S, Belzberg AJ, Eng J, Carrino JA, et al: Spectrum of magnetic resonance imaging findings in congenital lumbar spinal stenosis. World J Clin Cases 2:883-887, 2014

40. Steurer J, Roner S, Gnannt R, Hodler J: Quantitative radiologic criteria for the diagnosis of lumbar spinal stenosis: a systematic literature review. BMC Musculoskelet Disord 12:175, 2011

41. Videman T, Battié MC, Ripatti S, Gill K, Manninen H, Kaprio J: Determinants of the progression in lumbar degeneration: a 5-year follow-up study of adult male monozygotic twins. Spine (Phila Pa 1976) 31:671-678, 2006
42. Vo NV, Hartman RA, Patil PR, Risbud MV, Kletsas D, Iatridis JC, et al: Molecular mechanisms of biological aging in intervertebral discs. J Orthop Res 34:1289-1306, 2016

43. Weishaupt D, Zanetti M, Boos N, Hodler J: MR imaging and CT in osteoarthritis of the lumbar facet joints. Skeletal Radiol 28:215-219, 1999

44. Williams FM, Manek NJ, Sambrook PN, Spector TD, Macgregor AJ: Schmorl's nodes: common, highly heritable, and related to lumbar disc disease. Arthritis Rheum 57:855860,2007

45. Yong-Hing K, Kirkaldy-Willis WH: The pathophysiology of degenerative disease of the lumbar spine. Orthop Clin North Am 14:491-504, 1983

\section{Disclosures}

The authors report no conflict of interest concerning the materials or methods used in this study or the findings specified in this paper.

\section{Author Contributions}

Conception and design: all authors. Acquisition of data: Kitab, Lee. Analysis and interpretation of data: all authors. Drafting the article: all authors. Critically revising the article: all authors. Reviewed submitted version of manuscript: all authors. Approved the final version of the manuscript on behalf of all authors: Benzel. Study supervision: Benzel.

\section{Correspondence}

Edward C. Benzel: Cleveland Clinic, Cleveland, OH. benzele@ ccf.org. 